\title{
The Effect of Prophylactic Antibiotics on Post Laparoscopic Cholecystectomy Infectious Complications: A Double-Blinded Clinical Trial
}

\author{
Ali Asghar Darzi ${ }^{1}$, Alieh Nikmanesh², Farhad Bagherian ${ }^{3}$ \\ ${ }^{1}$ Assistant Professor, Department of Surgery, Clinical Research Development Center, Babol University of Medical \\ Sciences, Babol, Iran \\ ${ }^{2}$ Clinical Research Development Center, Shahid Beheshti Hospital, Babol University of Medical Sciences, Babol, \\ Iran \\ ${ }^{3}$ Assistant Professor, Clinical Research Development Center, Shahid Beheshti Hospital, Babol University of \\ Medical Sciences, Babol, Iran
}

\section{Type of article: Original}

\begin{abstract}
Background: Laparoscopic cholecystectomy (LC) is one of the most common surgeries in laparoscopic surgery. Although, it is believed that LC has low-risk for post-operative infectious complications, the use of a prophylactic antibiotic is still controversial in elective LC.

Objective: To determine the impact of prophylactic antibiotics on postoperative infection complications in elective laparoscopic cholecystectomy.

Methods: In this double-blind, placebo-controlled, randomized, clinical trial, patients who were candidates for elective LC, from March 2012 to 2015, in four hospitals in Babol, Iran, were studied. Patients were allocated randomly to two groups, i.e., group C: Cefazolin $(n=182)$ and group P: placebo $(n=247)$. Group C received $1 \mathrm{~g}$ of Cefazolin 30 minutes before anesthesia and and then, six and 12 hours after anesthesia. Group P patients received $10 \mathrm{ml}$ of isotonic sodium chloride solution. Age, gender, type of gallbladder diseases (stone, polyp, or hydrops), the length of post-operative hospitalization, frequency of gallbladder rupture, the duration of surgery, and the kinds of complications associated with infections were collected for each patient in the two groups. The data were analyzed by IBM-SPSS version 20 , using the t-test and the chi-squared test, and a p-value $<0.05$ was considered as significant.
\end{abstract}

Results: There were no significant differences between the two groups in terms of gender (C versus P: 18 (9.9\%) male versus $22(9 \%) ; p=0.74)$, age $(C$ versus $P: 43.75+13.30$ years versus $40.91+13.05 ; p=0.20)$, and duration of surgery ( $\mathrm{C}$ versus $\mathrm{P}: 34.97 \pm 8.25$ min versus $34.11 \pm 8.39 ; \mathrm{p}=0.71)$. There were no significant differences between the two groups in the incidences of post-operative infection (C versus P: $3(1.7 \%)$ versus 5 $(2 \%) ; p=0.99)$ and rupture of the gallbladder (C versus P: $14(7.8 \%)$ versus $17(6.8 \%) ; p=0.85)$. No other postoperative systemic infectious complications (e.g., sepsis, pneumonia, or urinary tract infection) were found in either group.

Conclusion: For patients who underwent laparoscopic cholecystectomy (LC), prophylactic antibiotics had no important role in the prevention of infections; so these antibiotics apparently are not necessary in treatment, and they are not recommended for patients with laparoscopic cholecystectomy as low-risk selective antibiotics.

Trial registration: The trial was registered at the Iranian Clinical Trial Registry (http://www.irct.ir) with the IRCT identification number IRCT2013070413865N1.

Funding: This research was supported financially by the Research Council of Babol University of Medical Sciences.

Keywords: Antibiotic prophylaxis, Surgical wound infection, Laparoscopic cholecystectomy

\section{Corresponding author:}

Assistant Professor Dr. Farhad Bagherian, Clinical Research Development Center, Shahid Beheshti Hospital, Babol University of Medical Sciences, Babol, Iran. Tel: +98.9111152946, Email: dr_f_bagherian@yahoo.com

Received: December 03, 2015, Accepted: March 04, 2016, Published: May $201 \overline{6}$ iThenticate screening: March 04, 2016, English editing: March 12, 2016, Quality control: May 02, 2016

(C) 2016 The Authors. This is an open access article under the terms of the Creative Commons Attribution-NonCommercialNoDerivs License, which permits use and distribution in any medium, provided the original work is properly cited, the use is non-commercial and no modifications or adaptations are made. 


\section{Introduction}

In patients with symptomatic cholelithiasis during open cholecystectomy operations, the first choice for treatment should be laparoscopic cholecystectomy (1-2) because of the slight probability of post-operative infections due to the creation of tiny wounds as well as tissue damage, which is less common in LP than open surgery (1). Surgical site infections (SSIs) are infections that occur in the wound created by an invasive surgical procedure, and they are the common cause of healthcare-associated infections (1-4). Three meta-analyses based on the use of retrospective studies indicated that, after cholecystectomy, the mean ratio of infectivity by microorganisms in the wound sites was in the range of $0.4-1.1 \%(2-4)$. The use of prophylactic antibiotics in the study was shown to prevent surgical site infections (SSIs), thereby preventing the obvious infectious side effects in open cholecystectomy; of course, according to several surveys that have been conducted in various parts of the world, these antibiotics are neither appropriate nor necessary for this purpose (5-13). However, there is no consensus on these considerations, and many surgeons still use antibiotic prophylaxis in laparoscopic cholecystectomy and also recommend the administration of prophylactic antibiotics (13-18). However, these meta-analyses were conducted at a different time, and on studies with relatively small sample sizes. Cefazolin - a first-generation cephalosporin - has the favorable pharmacokinetic properties of sufficient distribution to the wall of the gallbladder and a high concentration in the bile (19, 20). Because of its low toxicity, broad-spectrum anti-microbial effect, and low cost, a single dose of the antibiotic cefazolin is effective in patients with open cholecystectomy and other biliary surgery (21, 22). Thus, it is the antibiotic that is recommended by the U.S. Center for Disease Control and Prevention as being suitable for preventing SSIs $(23,24)$. However, to date, the effectiveness of Cefazolin on post-LC infective complications remains unclear. The aim of this study was to determine the efficacy of prophylactic Cefazolin on the rate of post laparoscopic cholecystectomy infectious complications.

\section{Material and methods}

\subsection{Study design}

This was a double-blinded, randomized, clinical trial conducted on patients who were candidates for elective LC due to symptomatic gallbladder stones or polyps and who were referred to four major hospitals in Babol, Iran, from March 2012 to March 2015.

\subsection{Study population}

The inclusion criteria were ages more than 18 years old and a first-time abdominal surgery. The exclusion criteria were patients who were younger than 18 and older than 75, antibiotic consumption in seven days before the LC, immune compromised patients, history of acute cholecystitis in the six months prior to admission, concomitant choledocholithiasis, intrahepatic duct stones, evidence of cholangitis and/or obstructive jaundice and gallstone pancreatitis, previous biliary tract surgery or previous endoscopic retrograde colangiopancreato- garaphy within a week before the surgery, diabetes mellitus, massive bleeding during surgery, converting laparoscopy to laparotomy, cephalosporin or beta-lactam allergy, sensitivity, or anaphylaxis, major thalassemia, and empyema.

\subsection{Sample size determination}

According to previous studies that showed an overall rate of infection of $1.1 \%$ (4), we estimated a sample size of 167 in each group using $\alpha$ value of 0.05 with a power of $80 \%$ and a precision of $1 \%$.

\subsection{Blinding and allocation}

Patients were allocated randomly using closed envelopes that contained one of the intervention protocols. They were allocated to two groups, i.e., group C: Cefazolin group $(n=182)$ and group P: Placebo group $(n=247)($ Figure 1). The intervention plan of each group was prepared by a nurse who was not a member of our research team, and the plan was delivered to the anesthesiologist. The patients were not aware of the type of solution that was used. The medical staff and the patient were unaware of the content of the solution.

\subsection{Interventions}

Group C patients received 1 gr of Cefazolin 30 minutes before anesthesia and and then, six and 12 hours after anesthesia. Group P patients received $10 \mathrm{ml}$ of isotonic sodium chloride solution with the same prescribing method of Cefazolin. Operations were conducted on all of the patients using reusable laparoscopic instruments that were sterilized with ethylene oxide. The skin was prepared with a 10\% povidone-iodine solution. LC was done with a 4 trocar standard technique; a 10-mm trocar was placed with the open technique through an infra-umbilical incision (Hasson). A 2-0 non-absorbable, monofilament suture was used to close the incision, but the other ones were applied under direct vision as follows: 5-mm trocar on the midclavicular line, 10-mm trocar in the epigastrium, and 5-mm 
trocar in the right flank in line with the gallbladder fundus; the extraction hole created by the trocar in the epigastric region was opened to remove the ruptured gallbladders that had severe inflammation and friability using a plastic bag and positional peritoneal irrigation without any drain, and 3-0, non-absorbable, monofilament sutures were used in the other incisions.

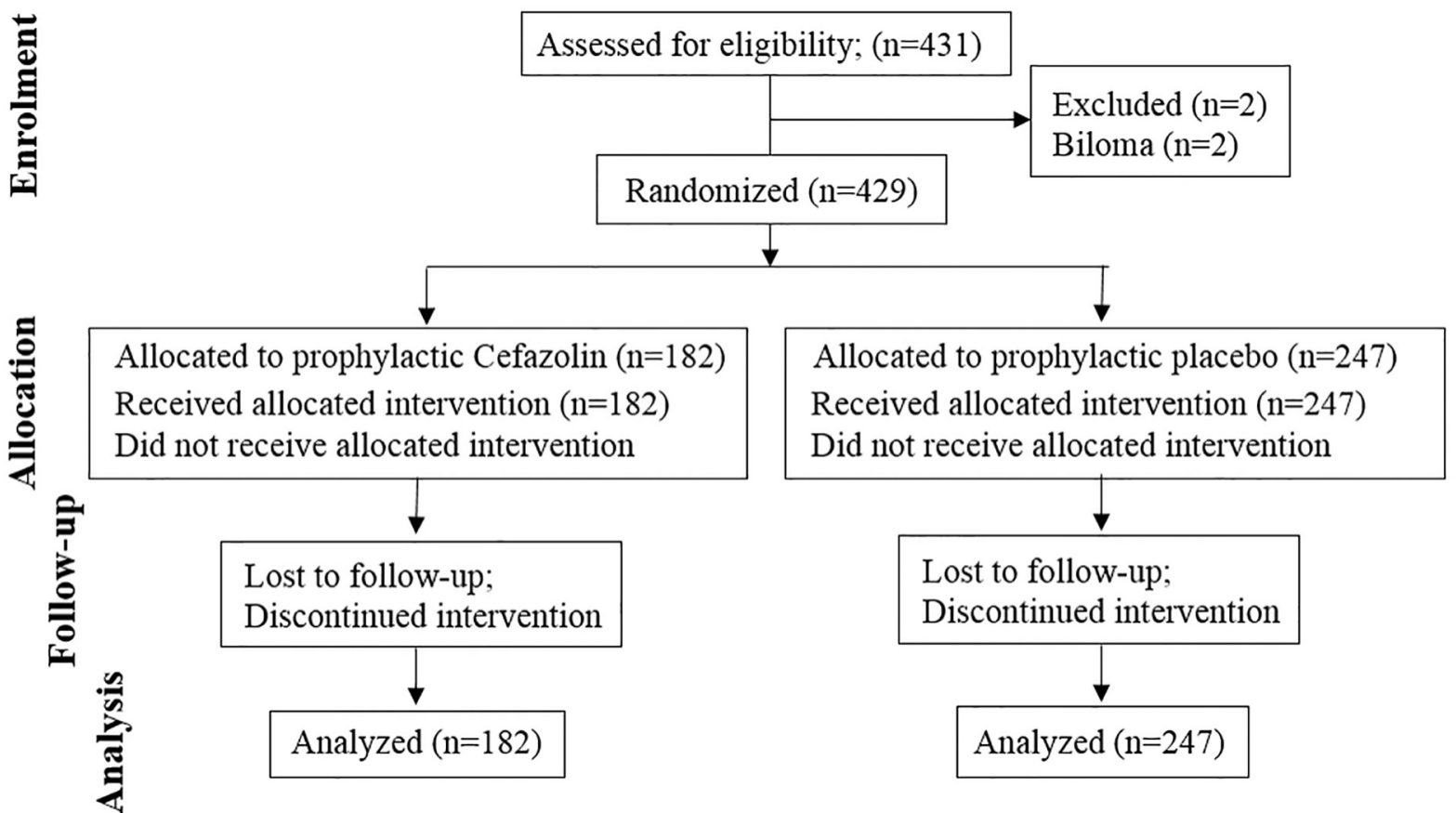

Figure 1. CONSORT diagram showing how the patients undergoing laparoscopic cholecystectomy were recruited and handled during the course of the study

\subsection{Outcomes}

Before the interventions, the subjects' genders and ages were documented. During the operation, surgery time and evidence of ruptured gallbladder also were recorded. The post-operative course was monitored, and the duration of hospital stay and any evidence of superficial SSI or any incidents, such as fever $\left(>38^{\circ} \mathrm{C}\right.$, temperature taken twice a day, excluding the first postoperative day), infection of the trocar site (purulent drainage from the surgical sites), and intra-abdominal collection of pus were recorded in checklists. After being discharged from the hospital, the patients underwent weekly, clinical, post-operative monitoring for SSI for a one-month period.

\subsection{Ethics}

This study was approved by the Ethics Committee of Babol University of Medical Sciences, and all of the subjects' parents were informed regarding the details of the study, and they signed a consent form. This study was registered in the Iranian Registry of Clinical Trials with the registration number of IRCT 20130704138651.

\subsection{Statistical analysis}

All of the variables had a normal distribution. Statical analysis, such as the t-test, chi-squared test, and 'Fisher exact test,' as appropriate, were done using IBM-SPSS version 20 considering a p-value $<0.05$ as significant.

\section{Results}

\subsection{Baseline characteristics}

Four hundred and twenty-nine patients, including 40 males and 389 females with a mean age of $42.08 \pm 13.1$ years, were enrolled in two groups, i.e., Group C $(n=182)$ and Group P $(n=247)$. There was no statistically significant difference between the two groups in term of gender $(p=0.74)$, age $(p=0.2)$, or the duration of surgery $(p=0.17)$ (Table 1). 
Table 1. Baseline characteristics and surgical outcomes of patients who underwent laparoscopic cholecystectomy in the two groups, i.e., the cefazolin group and the placebo group

\begin{tabular}{|l|l|l|l|}
\hline Characteristics & Group cefazolin $(\mathrm{n}=182)$ & Group placebo $(\mathrm{n}=247)$ & $\mathrm{p}$-value \\
\hline Gender, male/female $\mathrm{n}(\%)$ & $18(9.9 \%) / 164(90.1 \%)$ & $22(9 \%) / 225(91 \%)$ & 0.74 \\
\hline Age, year $($ mean \pm SD) & $43.75 \pm 13.30$ & $40.91 \pm 13.05$ & 0.2 \\
\hline Rupture of Gallbladder, $\mathrm{n}(\%)$ & $14(7.8 \%)$ & $17(6.8 \%)$ & 0.85 \\
\hline Post-operative infection, $\mathrm{n}(\%)$ & $3(1.7 \%)$ & $5(2 \%)$ & 0.99 \\
\hline Duration of Operation, min (mean \pm SD) & $34.97 \pm 8.25$ & $34.11 \pm 8.39$ & 0.17 \\
\hline Length of Stay, day (mean \pm SD) & $1.02 \pm 0.12$ & $1.02 \pm 0.15$ & 0.71 \\
\hline
\end{tabular}

\subsection{Surgery outcomes}

The results of surgery indicated that the mean length of the LC operation was $34.43 \pm 8.25 \mathrm{~min}$ and that the rate of gallbladder rupture was $7.25 \%$. No significant different was observed between the two groups in the mean duration of the LC operation or the rate of gallbladder rupture (Table 1). Post-operative follow-up showed that the average duration of hospital stay was $1.02 \pm 0.13$ days. Post-LC superficial SSIs were observed in eight patients (1.9\%). Group $\mathrm{C}$ had three superficial SSIs (1.7\%), i.e., one at the umbilical port site and two at the epigastric incision site; in Group P, five patients had superficial SSIs (2\%), i.e., two at the umbilical port site and three at the epigastric port site. No other post-operative systemic infectious complications (e.g., sepsis, pneumonia, or urinary tract infections) occurred in either group. SSIs occurred in three out of 31 patients who had gallbladder rupture, and they occurred in five out of 398 patients without gallbladder rupture. The risk of infectious complications increased in patients who had ruptured gallbladders $(\mathrm{p}=0.001)$ and in male patients $(\mathrm{p}=0.03)$ (Table 2$)$.

Table 2. Comparison of the two groups of patients with and without infectious complications during one-month follow-up after laparoscopic cholecystectomy

\begin{tabular}{|l|l|l|l|}
\hline Characteristics & Infectious complications $(\mathrm{n}=8)$ & No complications $(\mathrm{n}=421)$ & $\mathrm{p}$-value \\
\hline Gender, male/female, $\mathrm{n}(\%)$ & $3(37.5 \%) / 5(62.5 \%)$ & $37(8.8 \%) / 384(91.2 \%)$ & 0.03 \\
\hline Age, year $($ mean \pm SD) & $45.88 \pm 15.88$ & $42.05 \pm 13.17$ & 0.41 \\
\hline Rupture of Gallbladder, $\mathrm{n}(\%)$ & $3(37.5 \%)$ & $28(6.7 \%)$ & 0.01 \\
\hline Duration of Operation, min (mean \pm SD) & $37.5 \pm 11.33$ & $34.42 \pm 8.22$ & 0.30 \\
\hline Length of Stay, day (mean \pm SD) & $1.00 \pm 0.0001$ & $1.02 \pm 0.14$ & 0.74 \\
\hline
\end{tabular}

\section{Discussion}

Our data showed that the overall rate of SSIs after LC was just 1.9\%, and it was not related to the use of a Cefazolin $(1 \mathrm{~g})$, which was lower than the rate of post-LC SSIs that has been reported in the literature, i.e., about $0.4 \%$ and $6.3 \%(4,6,8,13,15,24)$. The patients treated with or without prophylactic antibiotics showed different rates of SSIs, i.e., about $1.7 \%$ and $2.1 \%$, respectively, but the difference was not statistically significant. Actually, thesde rates were lower than the rates reported in other studies on open cholecystectomy $(4,25)$. In open cholecystectomy and other biliary surgery, Cefazolin is an effective antibiotic $(18,19)$. Also, studies have shown that, for induction of anesthesia or immediately before cutting in clean or clean-contaminated procedures, cephalosporin should be adminsistered intravenously as a single dose (22). However, the aim of antimicrobial prophylaxis is to reduce the number of microorganisms to such an extent that the defense mechanism of the host can effectively prevent infection by the contaminating microorganisms; it is not to completely eradicate microorganisms from the tissue (26). Whether antibiotic prophylaxis has any effect on the occurrence of postoperative infections in LC remains controversial $(2,4,5,7,14,15,27-30)$. Infectious side effects in laparoscopic cholecystectomy can be prevented mainly by administering prophylactic antibiotics (14-16), and these results were contrary to other findings obtained from several prospective surveys, so that the use of these antibiotics are unnecessary due to the low rates of infection during LC $(4,5,7,34)$. The various benefits of laparoscopy categorized as an elective method include less postoperative pain, shorter hospital stay, faster resumption of food intake and work, and a significant reduction in perioperative infectious complications $(1,31-33)$. Similar to previous studies, our results showed that there were no significant differences in the infection rate between the two groups of users of prophylactic antibiotic. Many reports also have indicated that wound infections are not related to rupture of gallbladders $(5,35)$. However, like other studies, our study also demonstrated that ruptures of the gallbladder contributed to the increased rates of postoperative infections $(38,39)$. Perforation during gallbladder surgery is attributed to traction, grasping, dissection, and removal of the gallbladder, which is likely to occur in 11 to $35 \%$ of LC cases $(4,7,14,34)$. In this study, rupture of the gallbladder occurred in 7.7 and $6.9 \%$ of patients in groups $\mathrm{C}$ and $\mathrm{P}$, respectively. There was a significant 
association between intraoperative gallbladder rupture and SSI $(p=0.001)$, whereas many reports have indicated that wound infections were not related to rupture of the gallbladder $(5,35)$. Patients with laparoscopic interventions treated by antibiotic prophylaxis were examined by Goldfan and Birkenmeier in 1990 within 98 randomized works, and they concluded that these antibiotics are not necessary in low-risk patients (37). According to the results of this and other studies, it should be noted that the causes of the low incidence of infections after laparoscopy can be attributed to minor surgical trauma, patient mobilization, faster resumption of permitted nutrition, and avoiding the administration of prophylactic antibiotics $(7,9)$. Other researchers have shown that major infectious complications, such as bile leak, intra-abdominal abscesses, and acute pancreatitis, usually are caused by technical problems instead of prophylactic antibiotics, so various parameters, including the delicacy of surgical techniques and other nonantibiotic-based physical and prophylactic methods, are considered more significant in the prevention process $(7,8$, 36). Other substantial factors of SSIs are associated with mechanical damage to tissues and contamination with the microflora from the skin $(5,10,25,35,36)$.

\section{Conclusions}

Considering the low rate of observed post-LC operation SSI in this study and the fact that there was no significant different between the two groups of patients who used prophylactic antibiotics and those who did not, it seems that the use of Cefazolin does not lower the rate of SSIs. Therefore, the use of prophylactic antibiotics is not recommended for patients undergoing $\mathrm{LC}$.

\section{Acknowledgments:}

We thank Mrs. Sakineh Kamali Ahangar, who is on the staff of the Clinical Research and Development Group at Shahid Beheshti Hospital in Babol, Iran, for her scientific support during this trial.

\section{Funding:}

This research was supported financially by the Research Council at Babol University of Medical Sciences. The authors received no financial assistance for the authorship and publication of this article.

\section{Trial registration:}

The trial was registered at the Iranian Clinical Trial Registry (http://www.irct.ir) with the IRCT identification number IRCT2013070413865N1.

\section{Conflict of Interest:}

There is no conflict of interest to be declared.

\section{Authors' contributions:}

All authors contributed to this project and article equally. All authors read and approved the final manuscript.

\section{References:}

1) Shea JA, Berlin JA, Bachwich DR, Staroscik RN, Malet PF, McGuckin M, et al. Indications for and outcomes of cholecystectomy: a comparison of the pre and post laparoscopiceras. Ann Surg. 1998; 227: 343-50. doi: 10.1097/00000658-199803000-00005. PMID: 9527056, PMCID: PMC1191271.

2) McGuckin M, Shea JA, Schwartz JS. Infection and antimicrobial use in laparoscopic cholecystectomy. Infect Control Hosp Epidemiol. 1999; 20: 624-6. doi: 10.1086/501685. PMID: 10501264.

3) Shea JA, Healey MJ, Berlin JA, Clarke JR, Malet PF, Staroscik RN, et al. Mortality and complications associated with laparoscopic cholecystectomy. A meta-analysis. Ann Surg. 1996; 224: 609-20. doi: 10.1097/00000658-199611000-00005, PMID: 8916876, PMCID: PMC1235438.

4) Chang WT, Lee KT, Chuang SC, Wang SN, Kuo KK, Chen JS, et al. The impact of prophylactic antibiotics on postoperative infection complication in elective laparoscopic cholecystectomy: a prospective randomized study. Am J Surg. 2006; 191: 721-25. doi: 10.1016/j.amjsurg.2006.01.050. PMID: 16720138.

5) Koc M, Zulfikaroglu B, Kece C, Ozalp N. A prospective randomized study of prophylactic antibiotics in elective laparoscopic cholecystectomy. Surg Endosc. 2003; 17: 1716 -18. doi: 10.1007/s00464-002-8866y. PMID: 12802644.

6) Mahatharadol V. A reevaluation of antibiotic prophylaxis in laparoscopic cholecystectomy: a randomized controlled trial. J Med Assoc Thai. 2001; 84: 105-8. PMID: 11281486. 
7) Tocchi A, Lepre L, Costa G, Liotta G, Mazzoni G, Maggiolini F. The need for antibiotic prophylaxis in elective laparoscopic cholecystectomy: a prospective randomized study. Arch Surg. 2000; 135: 67-70. doi: 10.1001/archsurg.135.1.67. PMID: 10636350.

8) Higgins A, London J, Charland S, Ratzer E, Clark J, Haun W, et al. Prophylactic antibiotics for elective laparoscopic cholecystectomy: are they necessary? Arch Surg. 1999; 134: 611-4. doi: 10.1001/archsurg.134.6.611. PMID: 10367869.

9) Harling R, Moorjani N, Perry C, MacGowan AP, Thompson MH. A prospective, randomized trial of prophylactic antibiotics versus bag extraction in the prophylaxis of wound infection in laparoscopic cholecystectomy. Ann R Coll Surg Engl. 2000; 82: 408-10. PMID: 11103159, PMCID: PMC2503474.

10) Illig KA, Schmidt E, Cavanaugh J, Krusch D, Sax HC. Are prophylactic antibiotics required for elective laparoscopic cholecystectomy? J Am Coll Surg. 1997; 184: 353-6. PMID: 9100679.

11) Dobay KJ, Freier DT, Albear P. The absent role of prophylactic antibiotics in low-risk patients undergoing laparoscopic cholecystectomy. Am Surg. 1999; 65: 226-8. PMID: 10075297.

12) Kuthe SA, Kaman L, Verma GR, Singh R. Evaluation of the role of prophylactic antibiotics in elective laparoscopic cholecystectomy: a prospective randomized trial. Trop Gastroenterol. 2006; 27: 54-7. PMID: 16910066.

13) Lippert H, Gastinger J. Antimicrobial prophylaxis in laparoscopic and conventional cholecystectomy. Conclusions of a large prospective multicenter quality assurance study in Germany. Chemotherapy. 1998; 44: 355-63. doi: 10.1159/000007135. PMID: 9732152.

14) Uchiyama K, Kawai M, Onishi H, Tani M, Kinoshita H, Ueno M, et al. Preoperative antimicrobial administration for prevention of postoperative infection in patients with laparoscopic cholecystectomy. Dig Dis Sci. 2003; 48: 1955-9. doi: 10.1023/A:1026114203622. PMID: 14627340.

15) Shindholimath VV, Seenu V, Parshad R, Chaudhry R, Kumar A. Factors influencing wound infection following laparoscopic cholecystectomy. Trop Gastroenterol. 2003; 24: 90 -2. PMID: 14603831.

16) Dervisoglou A, Tsiodras S, Kanellakopoulou K, Pinis S, Galanakis N, Pierakakis S, et al. The value of chemoprophylaxis against Enterococcus species in elective cholecystectomy: a randomized study of cefuroxime vs ampicillin-sulbactam. Arch Surg. 2006; 141: 1162-7. doi: 10.1001/archsurg.141.12.1162. PMID: 17178957.

17) Sarli L, Pietra N, Costi R, Grattarola M. Gallbladder perforation during laparoscopic cholecystectomy. World J Surg. 1999; 23: 1186-90. doi: 10.1007/s002689900644. PMID: 10501883.

18) Westphal JF, Brogard JM. Biliary tract infections: a guide to drug treatment. Drugs. 1999; 57(1): 81-91. doi: 10.2165/00003495-199957010-00007.

19) Munro R, Sorrell TC. Biliary sepsis. Reviewing treatment options. Drugs. 1986; 31(5): 449-54. doi: 10.2165/00003495-198631050-00004. PMID: 3086069.

20) Wittmann DH, Condon RE. Prophylaxis of postoperative infections. Infection. 1991; 19(Suppl 6): S33744. doi: 10.1007/BF01715775. PMID: 1791080.

21) Kellum JM, Duma RJ, Gorbach SL, Sugerman HJ, Haynes BW Jr, Gervin A, et al. Single-dose antibiotic prophylaxis for biliary surgery. Cefazolin vs moxalactam. Arch Surg. 1987; 122: 918-22. doi: 10.1001/archsurg.1987.01400200068012. PMID: 3115228.

22) Nichols RL. Preventing surgical site infections. Clin Med Res. 2004; 2: 115-8. doi: 10.3121/cmr.2.2.115. PMID: 15931344, PMCID: PMC1069080.

23) Mangram AJ, Horan TC, Pearson ML, Silver LC, Jarvis WR. Guideline for prevention of surgical site infection, 1999. Hospital Infection Control Practices Advisory Committee. Infect Control Hosp Epidemiol. 1999; 20: 250 -78. doi: 10.1086/501620. PMID: 10219875.

24) Catarci M, Mancini S, Gentileschi P, Camplone C, Sileri P, Grassi GB. Antibiotic prophylaxis in elective laparoscopic cholecystectomy. Lack of need or lack of evidence? Surg Endosc. 2004; 18: 638-41. doi: 10.1007/s00464-003-9090-0. PMID: 14752639.

25) Den Hoed PT, Boelhouwer RU, Veen HF, Hop WC, Bruining HA. Infections and bacteriological data after laparoscopic and open gallbladder surgery. J Hosp Infect. 1998; 39: 27-37. doi: 10.1016/S01956701(98)90240-7.

26) Page CP, Bohnen JM, Fletcher JR, McManus AT, Solomkin JS, Wittmann DH. Antimicrobial prophylaxis for surgical wounds. Guidelines for clinical care. Arch Surg. 1993; 128(1): 79-88. doi: 10.1001/archsurg.1993.01420130087014. PMID: 8418785.

27) Meijer WS, Schmitz PI, Jeekel J. Meta-analysis of randomized, controlled clinical trials of antibiotic prophylaxis in biliary tract surgery. Br J Surg. 1990; 77(3): 283-90. doi: 10.1002/bjs.1800770315. PMID: 2138925. 
28) Yan RC, Shen SQ, Chen ZB, Lin FS, Riley J. The role of prophylactic antibiotics in laparoscopic cholecystectomy in preventing postoperative infection: a meta- analysis. J Laparoendosc Adv Surg Tech A. 2011; 21(4): 301-6. doi: 10.1089/lap.2010.0436. PMID: 21443433.

29) Sanabria A, Dominguez LC, Valdivieso E, Gomez G. Antibiotic prophylaxis for Patients undergoing elective laparoscopic cholecystectomy. Cochrane Database Syst Rev. 2010; (12): CD005265. doi: 10.1002/14651858.cd005265.pub2.

30) Mir MA, Malik UY, Wani H, Bali BS. Prevalence, pattern, sensitivity and resistance to antibiotics of different bacteria isolated from port site infection in low risk patients after elective laparoscopic cholecystectomy for symptomatic cholelithiasis at tertiary care hospital of Kashmir. Int Wound J. 2013; 10(1): 110-3. doi: 10.1111/j.1742-481X.2012.00963.x. PMID: 22414004.

31) Hardy KJ, Miller H, Fletcher DR, Jones RM, Shulkes A, McNeil JJ. An evaluation of laparoscopic versus open cholecystectomy. Med J Aust. 1994; 160(2): 58-62. PMID: 8309369.

32) Constant E, Janssen P, Nys JM, el Fouly PE, Lemmens F, Hachez L, et al. Prospective analysis of 192 consecutive cholecystectomies: a comparative study between laparoscopy and laparotomy. Acta Chir Belg. 1995; 95(6): 254-60. PMID: 8571715.

33) Berggren U, Gordh T, Grama D, Haglund U, Rastad J, Arvidsson D. Laparoscopic versus open cholecystectomy: hospitalization, sick leave, analgesia and trauma responses. Br J Surg. 1994; 81(9): 13625.

34) Uludag M, Yetkin G, Citgez B. The role of prophylactic antibiotics in elective laparoscopic cholecystectomy. JSLS. 2009; 13(3): 337-41. PMID: 19793473, PMCID: PMC3015970.

35) Gold-Deutch R, Mashiach R, Boldur I, Ferszt M, Negri M, Halperin Z, et al. How does infected bile affect the postoperative course of patients undergoing laparoscopic cholecystectomy? Am J Surg. 1996; 172: 272- 4. doi: 10.1016/S0002-9610(96)00105-5. PMID: 8862082.

36) Colizza S, Rossi S, Picardi B, Carnuccio P, Pollicita S, Rodio F, et al. Surgical infections after laparoscopic cholecystectomy: ceftriaxone vs ceftazidime antibiotic prophylaxis. A prospective study. Chir Ital. 2004; 56: 397-402. PMID: 15287637.

37) Goldfaden A, Birkmeyer JD. Evidence-based practice in laparoscopic surgery: perioperative care. Surg Innov. 2005; 12: 51-61. doi: 10.1177/155335060501200108. PMID: 15846447.

38) Suh SW, Park JM, Lee SE, Choi YS. Accidental gallbladder perforation during laparoscopic cholecystectomy: does it have an effect on the clinical outcomes? J Laparoendosc Adv Surg Tech A. 2012; 22(1):40-5. doi: 10.1089/lap.2011.0219. PMID: 22044492.

39) Emin Turk, Erdal Karagulle, Kivanc Serefhanoglu, Hale Turan, Gokhan Moray. Effect of Cefazolin Prophylaxis on Postoperative Infectious Complication in Elective Laparoscopic Cholecystectomy: A Prospective Randomized Study. Iranian red cresent med j. 2013; 15(7): 581-6. PMCID: PMC3871745. 